\title{
Rapid, Precise, and High-Sensitivity Acquisition of Paleomagnetic and Rock-Magnetic Data: Development of a Low-Noise Automatic Sample Changing System for Superconducting Rock Magnetometers
}

\author{
Joseph L. Kirschvink*, Robert E. Kopp a , Timothy D. Raub, \\ Christopher T. Baumgartner \\ Division of Geological and Planetary Sciences, California Institute of Technology, Pasadena, \\ CA, 91125, USA
}

\author{
John W. Holt \\ Institute for Geophysics, Jackson School of Geosciences, University of Texas at Austin, 10100 \\ Burnet Rd., Austin, Texas 78758, USA \\ * Corresponding author. (kirschvink@caltech.edu) \\ (a) Current Address: Department of Geosciences and Woodrow Wilson School of Public \& \\ International Affairs, Princeton University, Princeton, NJ 08544, USA.
}

\begin{abstract}
Among Earth sciences, paleomagnetism is particularly linked to the statistics of large sample sets as a matter of historical development and logistical necessity. Because the geomagnetic field varies over timescales relevant to sedimentary deposition and igneous intrusion, while the fidelity of recorded magnetization is modulated by original properties of rock units and by alteration histories, "ideal" paleomagnetic results measure remanent magnetizations of hundreds of samples at dozens of progressive demagnetization levels, accompanied by tests of magnetic composition on representative sister specimens. We present an inexpensive, open source system for automating paleomagnetic and rock magnetic measurements. Using vacuum pick-and-place technology and a quartz-glass sample holder, the system can in one hour measure remanent magnetizations, as weak as a few $\mathrm{pAm}^{2}$, of $\sim 30$ specimens in two vertical orientations with measurement errors comparable to those of the best manual systems. The system reduces the number of manual manipulations required per specimen $\sim 8$ fold.
\end{abstract}

Keywords: paleomagnetism; rock magnetism; sensitivity; automation Index Terms: 1594 Geomagnetism and Paleomagnetism: Instruments and techniques.

Received 12 October 2007; Revised 14 January 2008; Accepted 19 February 2008; Published 2 May 2008.

Citation: J. L. Kirschvink, R. E. Kopp, T. D. Raub, C. T. Baumgartner, and J. W. Holt (2008). Rapid, precise, and high-sensitivity acquisition of paleomagnetic and rock-magnetic data: Development of a low-noise automatic sample changing system for superconducting rock magnetometers, Geochem. Geophys. Geosyst. 9, Q05Y01, doi: 10.1029/2007GC001856.

An edited version of this paper was published by AGU. Copyright (C) 2008 American Geophysical Union. 
This paper is dedicated to the memory of Dr. William S. Goree (1935-2007), who revolutionized the field of paleomagnetism by developing and commercializing superconducting moment magnetometers for geophysical use.

\section{Introduction}

Rock units sampled for paleomagnetic study can preserve multiple magnetic vector components of varying stability, acquired at different times during the unit's geologic history. Half a century ago, As and Zijderveld [1958] recognized that progressive demagnetization could discriminate among multiple components. Subsequently, a variety of thermal, chemical, electromagnetic, and microwave demagnetization techniques have been developed for this purpose, and statistical tools such as principal component analysis systematically quantify fossil magnetization vectors revealed by progressive demagnetization experiments [Collinson, 1983; Kent, et al., 1983; Kirschvink, 1980; Schmidt, 1982].

A long-standing challenge in paleomagnetism is adequate averaging of the geomagnetic secular variation recorded by each of these multiple components, which is frequently obscured by natural and artificial random dispersion and by bias in the fidelity of the magnetic recording process. Workers considering a variety of problems have long noticed that few paleomagnetic studies employ a statistically sufficient number of samples from discrete rock units [Enkin, 2003; Tauxe and Kent, 2004; van der Voo, 1990]. Even so, the amount of manual labor involved in paleomagnetic data collection easily prolongs studies to excessive durations, and student attrition is relatively high.

The challenge of discriminating multiple magnetic components in a single sample and of measuring enough samples to average each component's dispersion accurately is compounded by the difficulty of isolating a given component in a given sample during progressive demagnetization. A variety of magnetic minerals commonly contribute to the magnetization of rocks, and multiple mineral populations may be present in individual paleomagnetic samples. Because the magnetic coercivity and unblocking temperature of different crystals of a single mineral phase vary due to the effects of size, shape, and petrologic context, and because a variety of magnetic minerals may alter or form during progressive thermal demagnetization experiments, it is seldom easy to predict a priori the best set of demagnetization levels at which to measure specimens cut from a sample suite. In Table 1, we list some temperature intervals of interest and concern for studies employing thermal demagnetization. It is easy to appreciate that many dozens of discrete demagnetization levels are required to assess the multi-component magnetization of a natural rock sample confidently.

Published paleomagnetic studies frequently report successful characterization of magnetic components in only $\sim 10 \%-70 \%$ (for sedimentary studies) or $\sim 70 \%-90 \%$ (for igneous studies) of samples collected in the field. We suspect the two major reasons for this significant sample-failure rate are (1) too few progressive demagnetization steps employed to discern or define magnetic components preserved in a sample adequately; and (2) too much external contamination of individual moment measurements, mostly by sample holders with inherent magnetizations on par with those of weaker sedimentary samples. As specimen magnetization drops below that of the sample holder, the specimens cease to provide useful data and exacerbate the problems caused by sample numbers that are frequently insufficient to average natural and artificial magnetization variation.

As challenging as these potential obstacles are today, paleomagnetic study made a quantum leap in the early 1970's when the introduction of superconducting magnetometers designed to measure room-temperature magnetic moment of rocks increased the speed of individual measurements [Fuller, et al., 1985; Goree and Fuller, 1976]. However, repeat measurements of individual specimens every $\sim 5-10$ seconds and specimen changing every minute or so requires prolonged attentiveness without much opportunity to multi-task, and the labor demanded for detailed demagnetization experiments tended to inspire short-cuts, such as progressively demagnetizing only a pilot group of specimens and then "batch"processing remaining specimens at a single, "best" step. Such methods are now recognized as statistically inadequate [Kirschvink, 1980], and studies using them are not considered reliable [van der Voo, 1990].

During the past three decades, numerous groups have attempted to reduce the laborintensity of paleomagnetic studies. The late Alan Cox of Stanford introduced computer-controlled 
Table 1. Frequently encountered magnetic minerals, unblocking temperature, and thermochemical transformations.

\begin{tabular}{ll}
\hline Magnetic Mineral & Range of typical unblocking temperatures \\
\hline Goethite & $70-120 \mathrm{C}$ \\
highly-oxidized magnetite & $50-150 \mathrm{C}$ \\
Greigite & $270-340 \mathrm{C}$ \\
Pyrrhotite & $305-320 \mathrm{C}$ \\
Titanomaghemite & $300-400 \mathrm{C}$ (but wide range) \\
Titanomagnetite & $300-500 \mathrm{C}$ (but wide range) \\
Magnetite & $565-580 \mathrm{C}$ \\
Titanohematite & $100-630 \mathrm{C}$ (but wide range) \\
Hematite & $650-680 \mathrm{C}$ \\
\hline & \\
\hline Magnetic lability & Range of typical reaction temperatures \\
\hline goethite $\rightarrow$ hematite & $100-150 \mathrm{C}$ \\
Fe-clay $\rightarrow$ magnetite & $180-220 \mathrm{C}$ \\
greigite $\rightarrow$ pyrrhotite & $180-340 \mathrm{C}$ \\
greigite $\rightarrow$ magnetite & $180-340 \mathrm{C}$ (oxidation-dependent) \\
pyrrhotite $\rightarrow$ magnetite & $400-500 \mathrm{C}$ (oxidation-dependent) \\
Fe-carbonate $\rightarrow$ magnetite & $450-550 \mathrm{C}$ (oxidation-dependent) \\
pyrite $\rightarrow$ pyrrhotite + magnetite & $480-540 \mathrm{C}$ (oxidation-dependent) \\
magnetite $\rightarrow$ titanomagnetite & $550-680 \mathrm{C}$ (exsolved in ilmenite) \\
\hline
\end{tabular}

alternating field demagnetization in the late 1970 s (W. Goree, pers. comm.). His instrument allowed individual specimens to be loaded once to undergo complete three-axis demagnetization, however his system still required several manual specimen changes per hour and did not accommodate thermal demagnetization.

Later development of superconducting magnetometers customized for long-core measurements [e.g., Nagy and Valet, 1993] allowed acquisition of high-resolution data from soft-sediment drill cores [e.g., Verosub, 1998]. Such datasets effectively produce "continuous" paleomagnetic records that arguably have revolutionized our understanding of the Pliocene and Quaternary geomagnetic record [e.g., Channell, et al., 2004; Valet, et al., 2005]. Even these long-core systems have shortcomings, though; early models generally could not support ancient paleomagnetic field investigations, which require discrete paleomagnetic samples from outcrop, as the signal was smeared over $\sim 10 \mathrm{~cm}$ windows. The resolution of modern long-core systems is generally $\sim 5 \mathrm{~cm}$, with data-processing capabilities of $\sim 2 \mathrm{~cm}$ [Roberts, 2006], but the magnetization of a long-core holding tray is generally greater than that of many important but weakly-magnetized sedimentary rocks, and this trace ferromagnetic contamination can preclude its use for many rock-magnetic experiments involving the acquisition of isothermal or anhysteretic remanent magnetizations [see Kobayashi, et al., 1995].

As paleomagnetic techniques have evolved, rock magnetic techniques have also advanced considerably [Dunlop and Ozdemir, 1997]. Modern techniques for elucidating composition and character of magnetic phases are laborintensive, frequently requiring hundreds of measurement steps per specimen [e.g., Egli, 2004]. Many samples of geological interest are too weakly magnetized to use standard magnetic susceptometers or vibrating sample magnetometers but could be characterized using analogous rock magnetic protocols implemented on more sensitive DC SQUID sensors.

Automating parts of the mechanical process of measuring discrete specimens enables higher- 


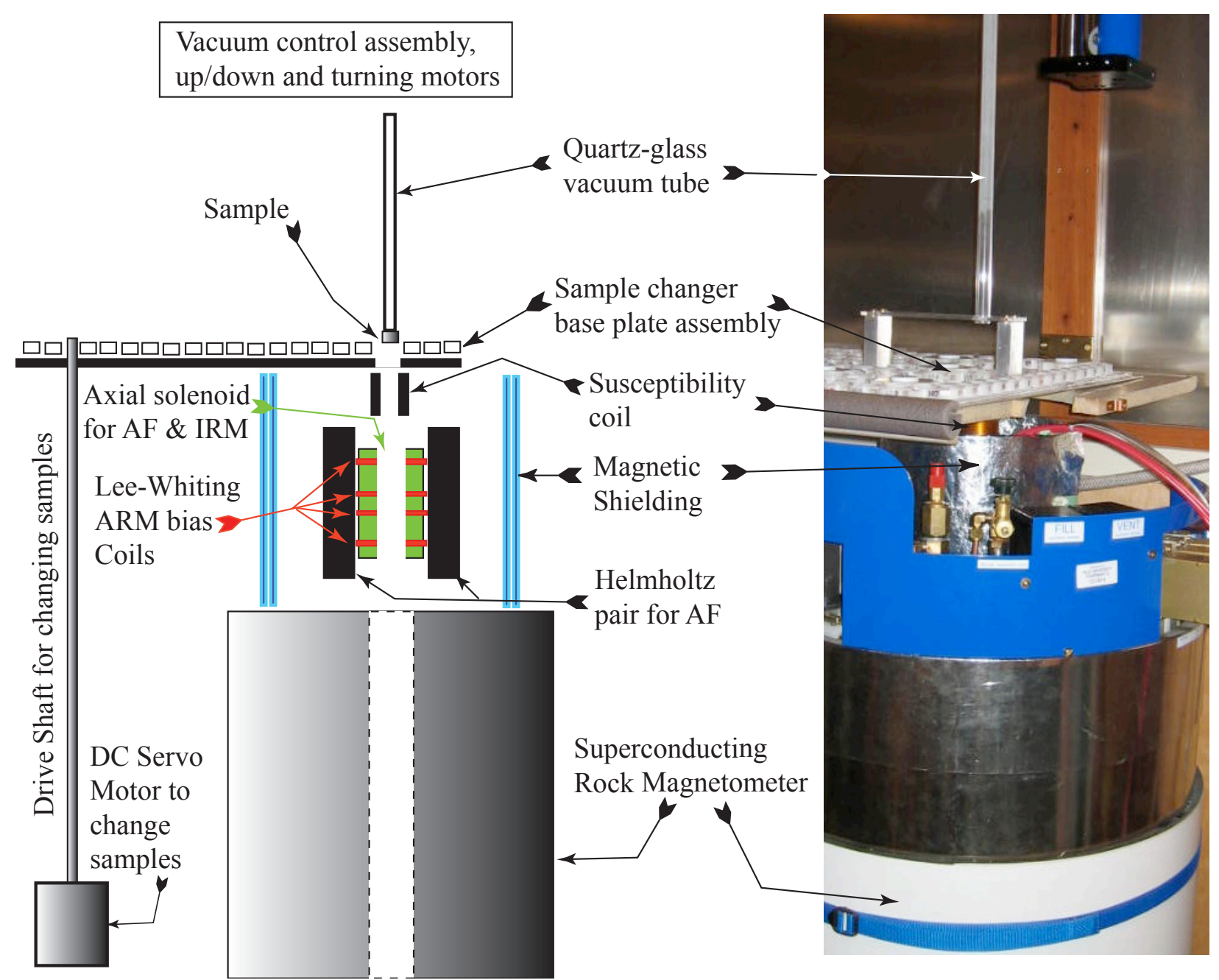

Figure 1: Block diagram and image of the sample changer system. Note that the system shown here only works for an SRM aligned in the vertical orientation; we have not solved the problem of automating samples for a horizontal magnetometer system.

throughput paleomagnetic measurements and frees researchers to focus on tasks of data analysis and scientific interpretation. In this article, we describe a relatively low-cost automatic sample changer for paleomagnetic and rock magnetic measurements built upon a vertical-access superconducting rock magnetometer (SRM), such as that marketed for many years by $2 \mathrm{G}$ Enterprises of Menlo Park, California. In addition to reducing the physical labor required by paleomagnetic measurements, the sample changer also increases the fraction of time a magnetometer can be used and provides a low-noise system for supporting a sample in the magnetometer's sense region that is suitable for rock-magnetic analyses.
The system described here is currently used at five universities in the United States (two systems at the California Institute of Technology, and one each at Occidental College, Yale University, the Massachusetts Institute of Technology, and the University of Texas at Austin) and at the United States Geological Survey laboratory at Menlo Park, with several more planned or under construction. Caltech started using a predecessor sample changer system in 1997 and has employed this system in its current form since 2004 .

Detailed blueprints for the system are available as online supplementary material. At the time of publication, the most recent version of the blueprints and the control software are also 


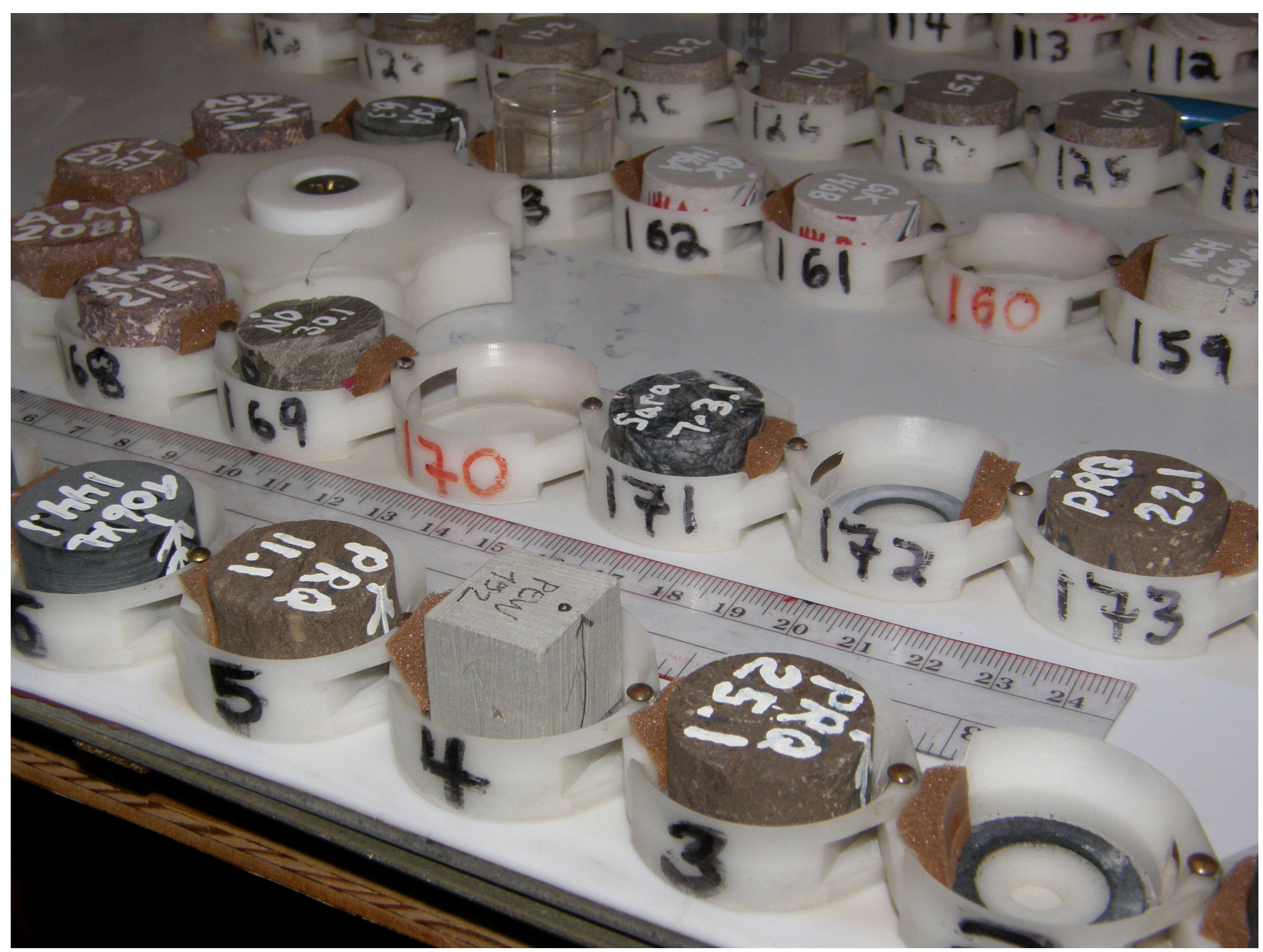

Figure 2: Delrin ${ }^{\mathrm{TM}}$ sample-changer cups, arranged in the 'snake-chain' assembly. To stop samples from wobbling on a single-point irregularity, a flat rubber " $O$ " ring is glued to the base of each cup. This forces even the most irregular samples to rest on at least 3 widely-spaced contact points, which does not always happen with a solid bottom of either plastic or rubber. We also placed a strip of light, self-adhesive weather-stripping foam on the back side of the cups to hold the specimens stable and snugly tangent to the edge of the circular base of each cup while the snake chain is moving. Although this results in the center of a typical specimen being offset by a few mm from the center of each cup, the user can tell the instrument what this average offset is for a group of samples via a 'fractional hole offset' parameter built into the software. During the sample pick-up and drop-off operations, this allows the sample changer to center the specimen itself under the quartz-glass tube while allowing it to pass through the center of one of the bottomless cups for the measurement process.

available through links at http:// paleomag.caltech.edu/.

\section{Hardware}

The sensitivity of most superconducting moment magnetometers currently in use is limited by the magnetic moments of sample holders used to move specimens into and out of the magnetometers' measurement region. Sample holders typically have magnetic moments two to three orders of magnitude greater than the root- mean-square instrument noise level of modern DC SQUID sensors $\left(\begin{array}{llllll}\sim & \mathrm{x} & 1 & 0^{-13} & \mathrm{Am}^{2}\end{array}\right)$. Straightforward calculations indicate that meaningful information can be preserved down to $\sim 10^{-16} \mathrm{Am}^{2}$ [Kirschvink, 1981; Weiss, et al., 2001], comparable to the magnetic moment of a single magnetotactic bacterium bearing a few single-domain magnetite crystals.

We have found that many industrial plastics (including virgin Teflon) contain ppblevels of ferromagnetic contaminants with rockmagnetic properties similar to that of fine-grained 
magnetite [e.g. Kobayashi, et al., 1995]. Although the concentrations of these contaminants are small, their intense magnetization coupled with the extraordinary sensitivity of DC SQUID sensors often requires the use of clean-lab techniques for measuring weakly-magnetized materials [Walker, et al., 1985]. Although it is possible to demagnetize a sample holder to measure the remanence moment of weakly magnetized rocks, many rock-magnetic experiments require exposing both a specimen and its holder to strong magnetizing fields. In practice, the moment of a sample holder determines the weakest specimens that can be measured on a system.

Figure 1 contains a schematic illustration and a photograph of our sample changer system. To minimize holder contamination, we employ quartz glass tubing with $\sim 1 \mathrm{~mm}$ thick walls. By soaking one end of the tubing in concentrated $\mathrm{HCl}$ or aqua regia for hours to days, it is possible to reduce ferromagnetic contamination to levels that are sometimes below measurement sensitivity. The $\sim 1.3 \mathrm{~m}$ long tube hangs from a chassis connected to two microprocessor-controlled DC servo motors (QuickSilver Controls, Inc., San Dimas, CA). These motors are located above the magnetic shielding of the room containing the SRM. The "turning motor" rotates the tube-bearing shaft of the chassis (at up to $40 \mathrm{~Hz}$ ), while the "Z-axis" motor moves the whole chassis up and down. In the present configuration, both motors run on a common $48 \mathrm{~V}$ DC supply, and their rotor positions are encoded optically to a precision of 1 part in 8000 and communicated to the controlling computer by an RS-232 communication link. (Motor position inaccuracies vary in proportion to user-specified speed and torque settings. For quick motion and high torque, real rotational precision is $\sim 0.5^{\circ}$ and real vertical precision is 200-300 microns, approximately 6-8 times the encoded precision.)

Within the shielded room, an aluminum tray is suspended flat above the SRM, with one $\sim 3 \mathrm{~cm}$ hole in the tray aligned above the magnetometer cavity. A belt of 200 cylindrical Delrin ${ }^{\mathrm{TM}}$ plastic cups, $3.5 \mathrm{~cm}$ in diameter and labeled consecutively, runs along the top of the tray, connected by a gear and no-slip pulley system to a DC servo motor dubbed the "changer motor." As this motor is strongly magnetic, it is located at least a meter below the sample tray and shielded; a brass or aluminum rod transmits torque to the chain of sample cups. As shown in Figure 2, the cups are tapered along the top to minimize jamming problems and are held together by brass pins in a continuous "snake chain." To minimize friction between the chain and the aluminum tray, a $\sim 1 \mathrm{~mm}$ thick Teflon sheet, chemically treated on one side to allow it to adhere to epoxy, is bonded to the top surface of the tray. The brass pins connecting "snake chain" cups also provide an orienting mark for aligning samples relative to the magnetometer axes. O-rings stamped from sheetrubber with self-adhesive backing are attached to the interior bottom of each cup and provide friction for holding samples in place. A thin strip of adhesive weather-stripping foam (like that used to insulate window sills and door frames) is attached to the backside of each sample cup to prevent specimens from becoming misaligned when the chain moves. Every tenth cup in the belt lacks a bottom, so that the magnetometer cavity is exposed when such a cup is on top of the hole on the tray. Other configurations for the snake chain are possible which would permit more samples to be held in the measurement queue.

The quartz tube is stabilized with a plastic guide $7.5 \mathrm{~cm}$ above the sample tray. Z-axis motion controls restrict the bottom of the quartz glass tube vertically in a range between a position $7.5 \mathrm{~cm}$ above the tray (the "home" position) and the SRM sense region (the "measure" position). The top of the tube is plumbed through a rotary junction and a flexible vacuum hose, which is connected to a brushless $800 \mathrm{~W}$ vacuum blower. A custom-built relay box with an RS-232 interface controls power to the vacuum blower and two solenoid valves that apply or disconnect the vacuum to the quartz tube. The whole pick-andplace system requires at least $\sim 2.0 \mathrm{~m}$ clearance above the level of the sample changer tray, though more clearance is favorable. It is advisable to anchor the Z-axis and vacuum motors to ceiling or wall space external to the magnetic shield surrounding the SRM, and this generally requires cutting a hole in the shielding, directly above the measurement port of the vertically-oriented SRM. (Small holes in DC shields do not significantly reduce the shielding effect, and magnetic anomalies produced by cutting holes in mu-metal or soft steel can be demagnetized with a small AC coil [Scott and Frohlich, 1985].)

Slightly below the sample changer tray and in the sample path to the SRM sense region, we have installed a nested coil set for alternating-field (AF) demagnetization. The set consists of an axial solenoid wrapped on a Phenolic coil form, and a 
pair of hefty Helmholtz coils oriented so that their peak field is centered on, but perpendicular to, that of the solenoid. Using a commercial AF demagnetization unit (Applied Physics Systems of Menlo Park, CA) with custom tuning and calibration, we reach peak alternating fields of $\sim 100 \mathrm{mT}$ with the Helmholtz pair and $\sim 350 \mathrm{mT}$ with the axial solenoid. We use a spare highcurrent relay on the commercial AF unit to connect the axial solenoid to a computercontrolled capacitive pulse-magnetization unit [marketed by ASC Scientific, following the design of Kirschvink, 1983], allowing the system to perform isothermal remanent magnetization (IRM) experiments. This relay allows the pulse polarity to be inverted, permitting backfield-IRM experiments to be performed for determination of median remanence coercivity and most of the Preisach distribution [Bate, 1962]; this contains much of the important information present in FORC diagrams [Carvallo, et al., 2005]. An additional carefully-crafted coil system based on the Lee-Whiting 4-coil design [Kirschvink, 1992; Lee-Whiting, 1957] and nested inside the Helmholtz pair provides a DC biasing field parallel to the axial field for use in generating uniform anhysteretic remanent magnetizations (ARMs). A small coil for measuring bulk susceptibility (model MS-2, Bartington Instruments, Oxford, UK) in conjunction with each measurement step is mounted on top of the AF coil set. The servomotors, SRM SQUID control boxes, the AF control unit, the susceptibility bridge, and the vacuum relay switches communicate with the controlling computer via an RS-232 protocol.

We have designed and built a custom control box for charging the capacitor in the IRM circuit up to $400 \mathrm{~V}$. This control box accepts a 16bit programmable analog voltage $(0-10 \mathrm{~V})$ produced by a commercially available I/O card (Measurement Computing, Norton, MA). That voltage controls a $15 \mathrm{~W}$ regulated $0-400$ VDC power supply (EMCO High Voltage Corporation, Sutter Creek, CA), capable of charging the 1.2 mfd capacitance to full voltage in approximately 1 minute. The voltage on the capacitor is monitored continuously using a 40:1 resistor bridge connected to a 16-bit analog-to-digital converter on the I/O card. When a stable peak voltage has been reached, a digital output line on the card is programmed to activate the high-current siliconcontrolled relay [Kirschvink, 1983], producing a single, unidirectional magnetic pulse in the axial coil (Fig. 1). This system allows the $\sim 1$ Tesla peak field to be controlled in steps of $\sim 15 \mathrm{uT}$ (1 part in 65,536).

A similar voltage-activated circuit controls the current flowing in the Lee-Whiting 4coil system for providing a static magnetic field for ARM experiments. This coil is aligned parallel to the axial solenoid and is nested within the Helmholtz pair, as shown on Fig. 1. It can produce static fields between 0 and $1.6 \mathrm{mT}$ with uniformity greater than $0.2 \%$ over the entire volume of a typical paleomagnetic specimen [Kirschvink, 1992]. To prevent damage to the controlling circuit, and inadvertent acquisition of an ARM during normal operation of the AF demagnetization system, we placed a small relay, normally held open, in series with the coil to block current flow. Similarly, to minimize the flow of currents induced in the Lee-Whiting coils during operation of the axial AF solenoid during the ARM acquisition process, we force the current to pass through a large inductor $(\sim 28 \mathrm{mH})$ that has been tuned with small capacitors to resonate at the same frequency as the axial Af solenoid (typically $700-800 \mathrm{~Hz}$ on our modified Applied Physics degaussing systems).

All of the field-producing circuits (both AF axes, IRM, and ARM) are calibrated using Hall-probe sensors capable of monitoring the peak magnetic field detected at frequencies $<10 \mathrm{kHz}$; in turn these probes are calibrated with reference static magnets traceable to the U.S. National Bureau of Standards.

\section{Operations and Software}

\section{Sample Preparation}

Oriented samples for use in the changer system are cut into right cylindrical specimens or discs of variable thickness using standard non-magnetic, diamond-rimmed coring tubes and saw blades. The sample changer can accommodate specimens as tall as $\sim 3 \mathrm{~cm}$, but the low-moment quartz-glass holder readily permits measurement of stronglyand moderately-magnetized specimens as thin as it is possible to cut ( $\sim 1 \mathrm{~mm}$ thickness). The "out of outcrop" up-dip azimuth vertical direction of each right cylindrical (or disc-shaped) specimen is marked with an arrow perpendicular to the top and bottom surfaces. To ensure proper orientation of the specimen when the sample changer retrieves 
it, it is crucial that the top and bottom surfaces of each specimen are parallel and flat. This is achieved easily using a commercially-available rock chopping saw with multiple diamondimpregnated blades and grinding wheels to modify imperfections. For soft sediment samples, we employ the $7 \mathrm{~cm}^{3}$ plastic boxes manufactured by Natsuhara Giken, Ltd., of Osaka, Japan.

As the sensing coils in the superconducting moment magnetometers generally employ a Helmholtz configuration [Fuller, et al., 1985], the size and shape of a sample is not important as long as it fits wholly within the $1 \%$ uniformity region for the coil design. This contrasts greatly with spinner magnetometers, where sample shape is critical [e.g. Collinson, 1983]. Direct measurements of the spatial response with a magnetized point dipole [usually a chiton tooth, e.g., Kirschvink and Lowenstam, 1979] indicate that the $1 \%$ uniformity region on a typical narrowbore rock magnetometer is $\sim 2 \mathrm{~cm}$, increasing to $\sim 3 \mathrm{~cm}$ if a $2 \%$ uniformity is deemed acceptable. These spatial characteristics agree well with detailed calculations of field patterns surrounding a pair of Helmholtz pickup coils of $\sim 8 \mathrm{~cm}$ diameter [Kirschvink, 1992], as used on many of these instruments. To ensure optimal positioning of each specimen, the vertical servomotor is programmed to measure the height of each specimen as it is picked up by counting steps between the tube's "home" position about the sample tray and the height at which critical torque is produced by specimen contact. This enables the system to center each specimen precisely in the middle of the magnetometer's sense region even if adjacent specimens have different thicknesses.

\section{System Operation}

Before users begin making measurements, they set up sample data files in simple ASCII format using a script written in VBScript for Microsoft Excel. This script includes routines for reducing sun-compass measurements generated by the Pomeroy orientation sleeve, but any orientation convention can be translated to the chosen reference frame. Once the files are created, the users identify the sample sets to be measured. For each sample set, a tag describing the current demagnetization step is associated with the set. The user can alternatively instruct the software to perform a series of AF demagnetization treatments or rock magnetic experiments on a sample set. In the normal operation mode, the user then places oriented specimens in the plastic cups on the sample changer tray and tells the software the plastic-cup number of each specimen in the set to be measured. Automatic measurements then commence.

The software (currently written in Microsoft Visual Basic) begins by measuring the magnetic moment of the quartz glass sample holder. It uses the changer motor to slide the belt of plastic cups until the nearest cup with an empty bottom is over the hole in the tray. Then it turns the up/down motor to move the bottom of the glass tube into the "zero" position, $\sim 20 \mathrm{~cm}$ above the center of the sense region, and records the measurements from the SQUID read-outs. Next, it lowers the tube into the sense region, measures it, and repeats the measurements after $90^{\circ}, 180^{\circ}$, and $270^{\circ}$ rotations of the tube. It then does a second "zero" position measurement and, correcting linearly for any baseline drift observed between the two zero measurements, subtracts the vector moment in the zero position from the four vector moment measurements of the tube. These four measurements are corrected for orientation, averaged, and then used to correct all subsequent sample measurements until the next blank holder measurement.

The up/down motors then lift the tube above the sample tray. The changer motor places a sample underneath the tube, and the up/down motor lowers the tube until an abrupt increase in motor torque indicates that it is touching the sample. A pair of solenoid valves then connects the quartz-glass tube to the vacuum blower, firmly holding the sample to the flat end of the quartz tube. The sample is lifted above the tray, the sample belt slides so that the nearest emptybottomed cup is underneath the tube, and the sample is measured in the same fashion as the holder. In positioning the sample, the software corrects for the sample height measured during the pickup process in order to center the sample in the magnetometer's sense region. For weak samples, multiple measurement blocks can be averaged together to improve the signal-to-noise ratio. (One measurement block is a set of four sample measurements in different rotational orientations bracketed by two zero measurements). The measured sample moment, with the holder moment subtracted, is recorded in the specimen data file, and the sample is returned to its cup.

By default, the software expects to run measurements on samples oriented in the down 
direction after running the measurements in the up direction. Therefore, after completing the up measurements, the software prompts the user, both on screen and by email, to flip the samples. (A script on a monitoring computer may also announce the text of the message, as well as any error messages, to users in the lab.) The software then repeats the measurements in the down direction and averages together the rotationcorrected "up" and "down" measurements, and the user is notified when measurements are completed. The sample changer is capable of processing $\sim 60$ samples per hour in one direction. Data analysis can then be performed using software such as PaleoMag [Jones, 2002] or PaleoMac [Cogne, 2003].

\section{Automatic Error Checking}

The software checks for measurements errors at two opportunities. First, for specimens with moments stronger than $500 \mathrm{pAm}^{2}$, it automatically computes several statistics after completing a measurement block. It calculates the circular standard deviation (CSD) of the measurements, which is defined as $81 / k^{1 / 2}$, where $k=(N-1) /(N-R)$, $N$ is the number of data points, and $R$ is the resultant vector [Creer, 1970]. If the CSD is above a user-specified angular threshold (by default $8^{\circ}$ ), it repeats the measurement block. Measurement blocks are also repeated if the mean rotationcorrected moment is less than the CSD of the rotation-corrected measurements, or if the mean rotation-correction moment is less than the norm of the induced moment (the portion of the moment that is rotation-invariant).

After completing measurements on all specimens, the software also scans for specimens with CSDs above a user-specified threshold (again, by default $8^{\circ}$ ) and displays their labels, locations in the belt, CSDs, total moment, and the ratio of the moment as measured in the up direction to the moment as measured in the down direction. It then prompts the user to re-measure those samples. Performing both up and down direction measurements allows the second error check to identify any samples that were poorly aligned in their sample cups and samples in which the NRM has become unstable.

\section{Measuring Weakly-Magnetized Samples}

Our magnetometer and sample changer system has been successfully used to measure bituminous Permian carbonates and white Cretaceous chalks with total moments as weak as few $\mathrm{pAm}^{2}$ (Figure 3 ), far weaker than typically measured in paleomagnetic studies. The sample changer system supports measuring such weak samples by averaging together multiple measurement blocks on a single sample and by re-measuring and $\mathrm{AF}$ demagnetizing the quartz glass sample tube after every nine samples. Periodic soaking of the quartz glass rod in concentrated acid $(\mathrm{HCl}$ or aqua regia), more frequent washing of the rod with alcohol, occasional cleaning of the plastic guide for the rod, and handling samples wearing particle-free plastic gloves also increases sensitivity, as can placing the entire operation in a dust and particle-free clean lab [e.g., Kirschvink, 1983, Walker, 1985 \#28]. On some systems, procedures to minimize radio-frequency interference on all interconnecting cables on the SRM also help reduce noise. With these techniques, we have been consistently able to reduce holder noise for some quartz tubes below the $1 \mathrm{pAm}^{2}\left(10^{-9} \mathrm{emu}\right)$ levels. By comparison, the intrinsic noise of the DC SQUID sensor, determined by running the system without a quartz tube in place, is $\sim 0.2 \mathrm{pAm}^{2}\left(\sim 2 \times 10^{-10}\right.$ emu).

When measuring weak samples, occasional obvious glitches (such as the $120^{\circ} \mathrm{C}$ step in Fig. $3 \mathrm{~A}$, possibly from a magnetic dust particle attaching to the sample) need to be identified by eye; individual specimens can then be cleaned and re-measured. Principal component analysis of the demagnetization data from Japan's bituminous Kamura limestone and from upper Cretaceous Tunisian chalk yield a respectable distribution of errors at intensities down to fit component moments of $10 \mathrm{pAm}^{2}$ (Figs. 3B, D, and E). The bituminous limestone data display an unambiguous two-polarity characteristic magnetization (Fig. 3C). It is our impression from using this system that sample holder noise is still the main factor limiting the ultimate resolution of DC-biased SQUID rock magnetometer systems.

\section{Alternating Field Demagnetization and Rock Magnetic Experiments}

In all currently installed systems, the sample changer system has coils for AF, IRM, and ARM experiments installed in-line beneath the sample 

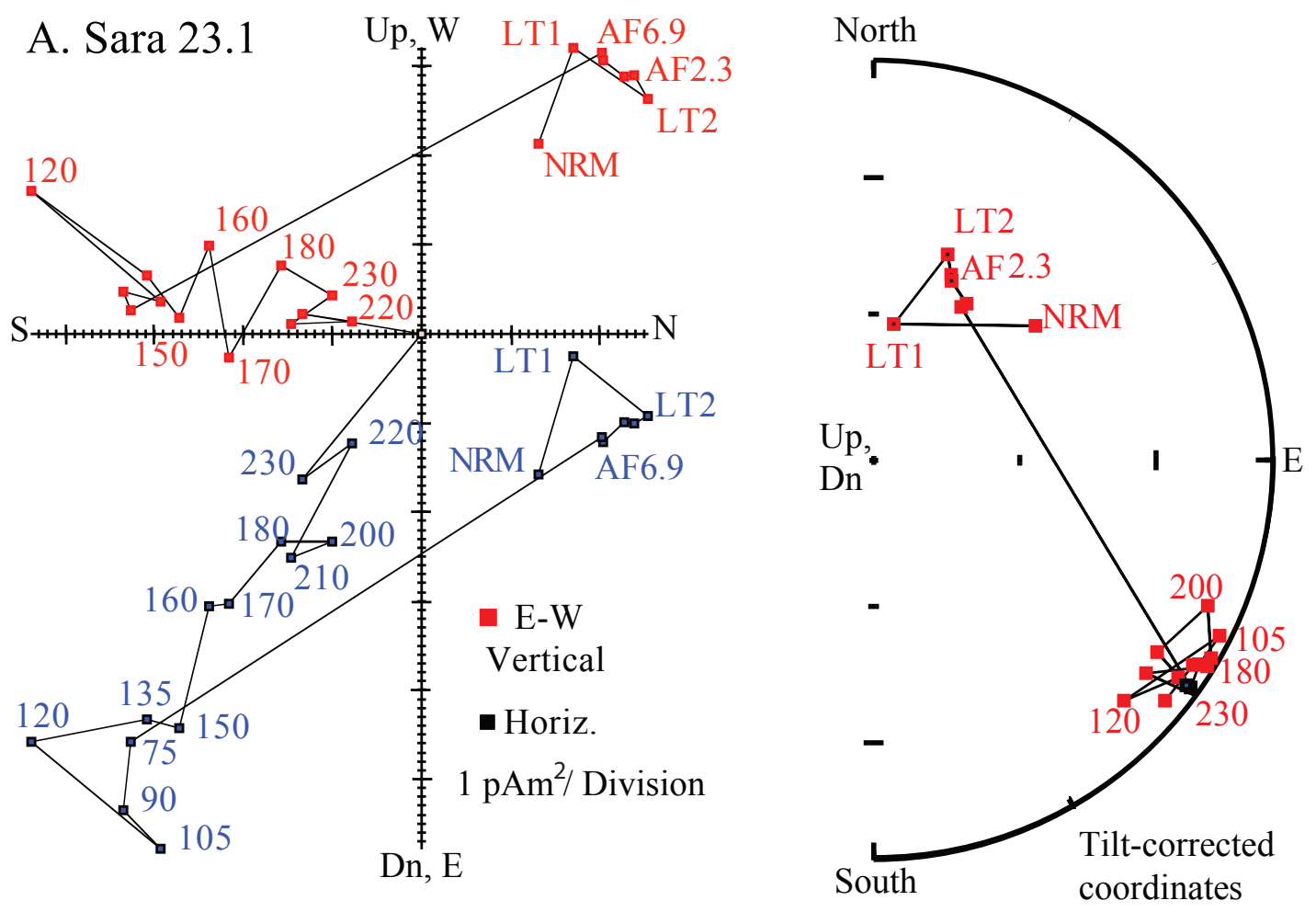

\section{B. Principal Component Intensities}

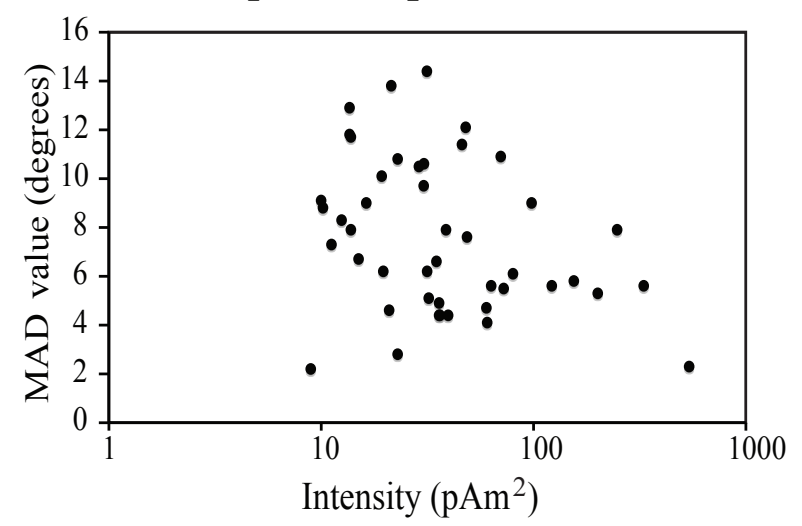

C. Principal Component Directions

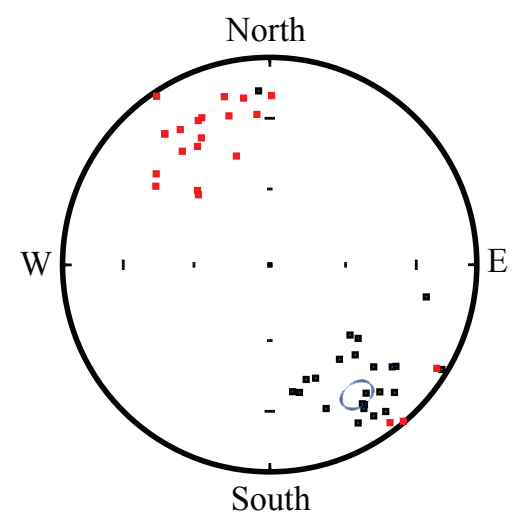

Figure 3: Paleomagnetic data from weakly magnetic Permian carbonates from Kamura, Kyushu, Japan [Isozaki, et al., 2007; Kirschvink and Isozaki, 2007] and from upper Cretaceous chalks from Ain Settara, Tunisia (unpublished data). (A) Vector and equal-area diagrams showing the progressive demagnetization of sample SARA 18, including low-temperature cycling in liquid nitrogen (LT), low alternating-field demagnetization, and thermal demagnetization. A subset of points are labeled; AF steps indicate field strength and thermal steps temperature $\left({ }^{\circ} \mathrm{C}\right)$. (B) A summary of the maximum angular deviation from the principal component analysis [Kirschvink, 1980] plotted against intensity of the fit principal component directions using the matrix-deconvolution $\mathrm{J} / \mathrm{J}_{0}$ routine of Jones [2002]. (C) Equal-area plot showing the directions of the most stable principal components for samples from the Kamura limestone. 


\section{Upper Cretaceous Chalks, Tunisia}
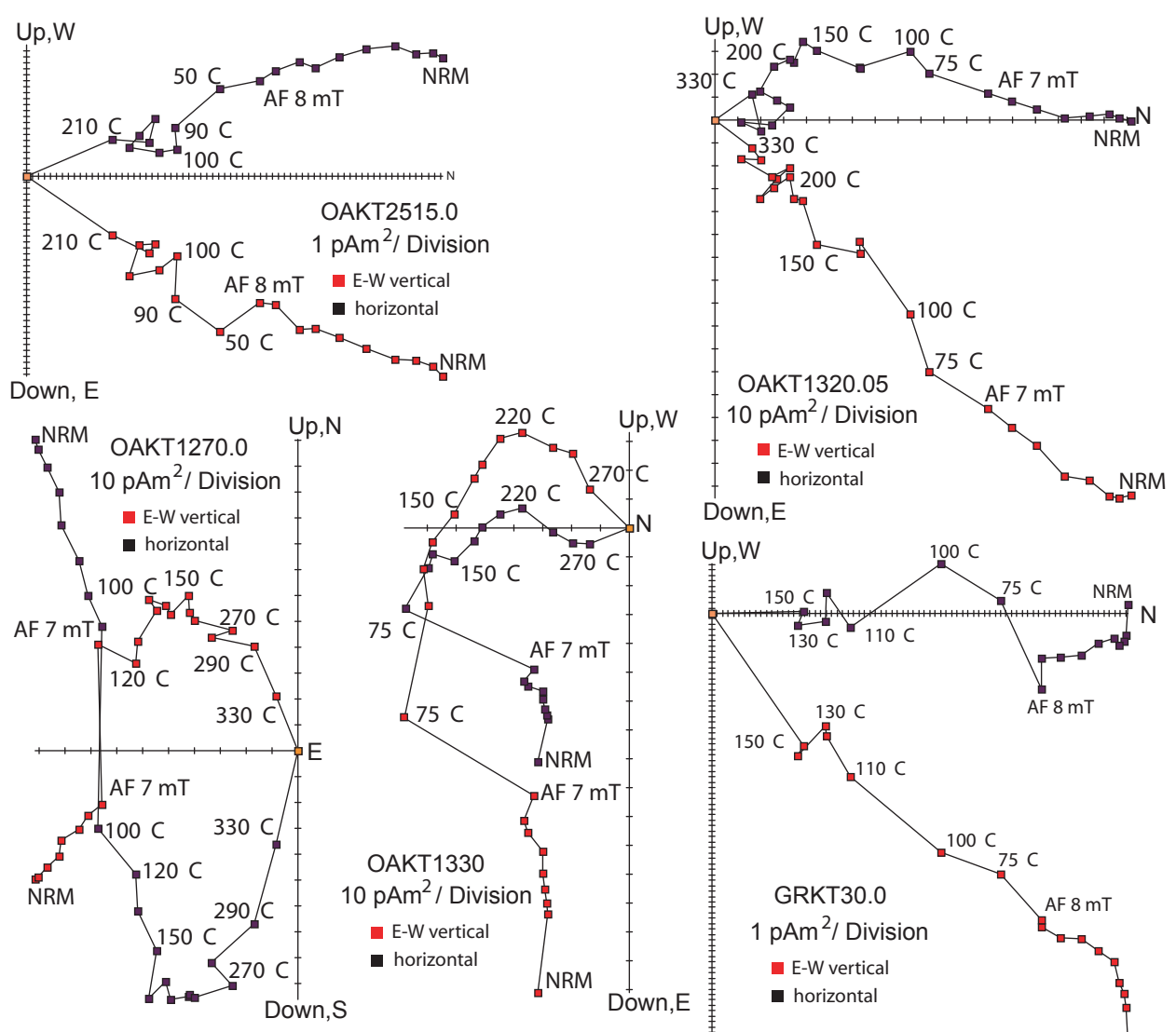

Down, E
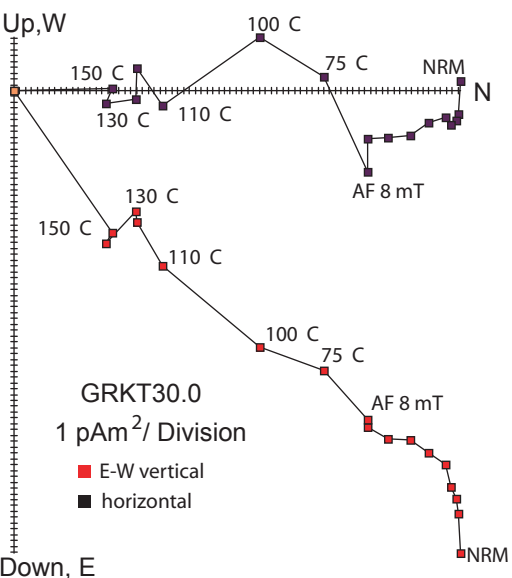

\section{E. Circular Standard Deviations}

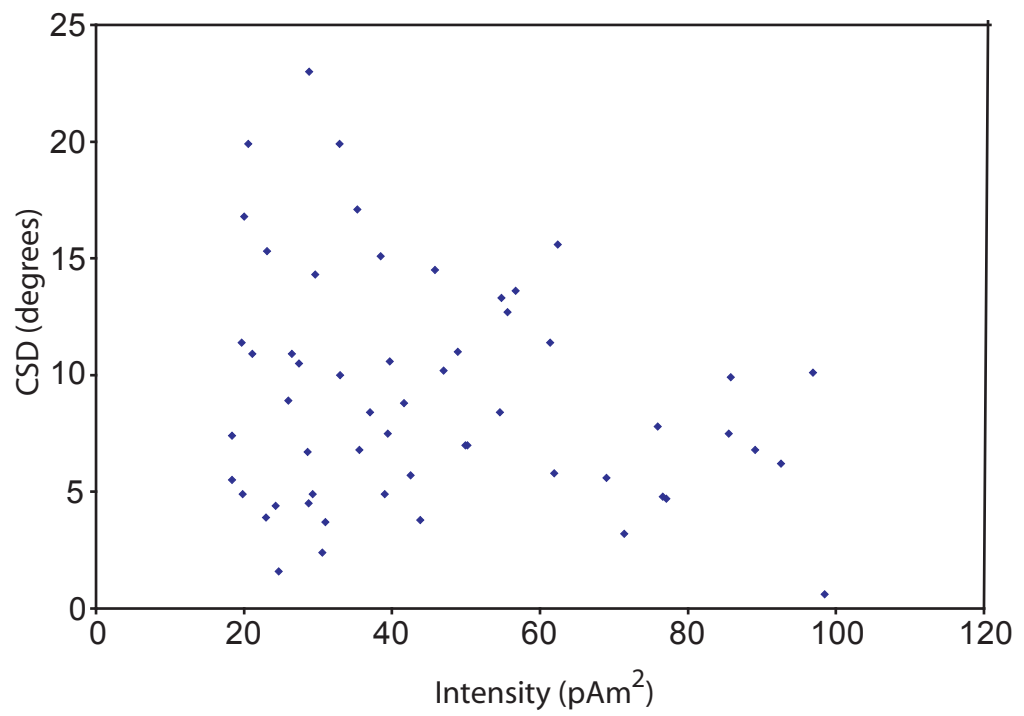

Figure 3, continued: (D) Five illustrative vector diagrams showing progressive demagnetization of Tunisian chalk samples, including low-temperature cycling, low alterating-field demagnetization, and thermal demagnetization. A subset of points are labeled. (E) A summary of the circular standard deviations of individual thermal demagnetization-level moment measurements for the illustrated Tunisian chalk samples. 
A. IRM: Acquistion \& AF

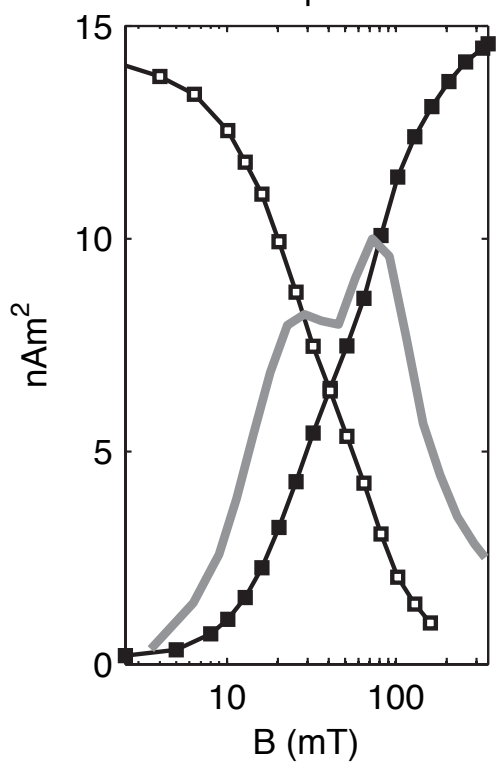

D. Fuller NRM test

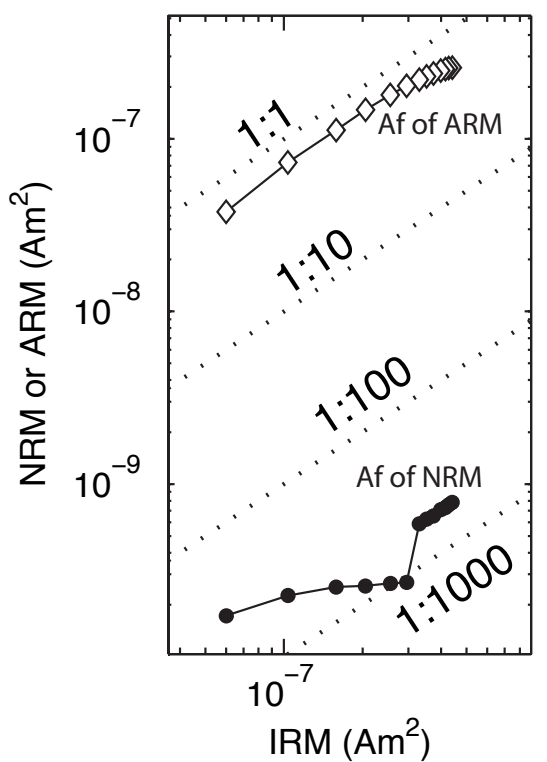

B. ARM Acquisition

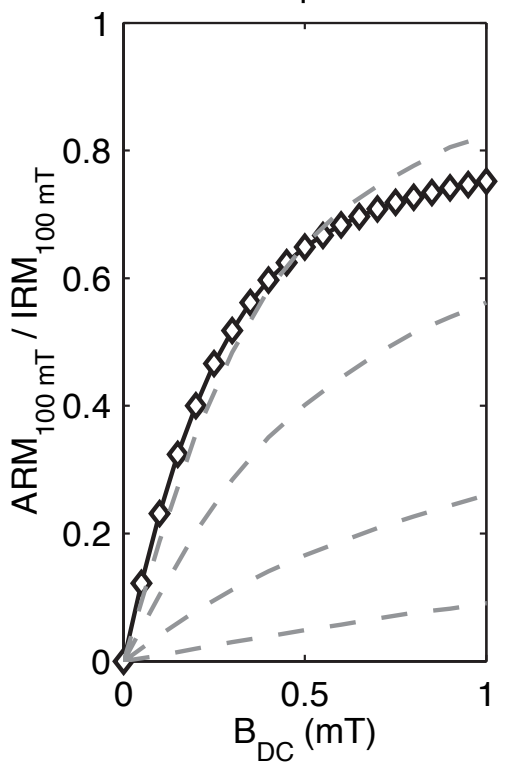

E. Susceptibility

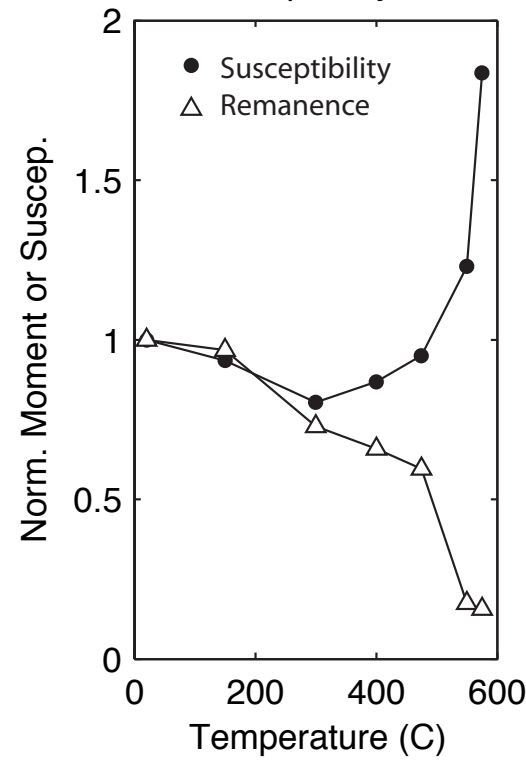

C. ARM Lowrie-Fuller

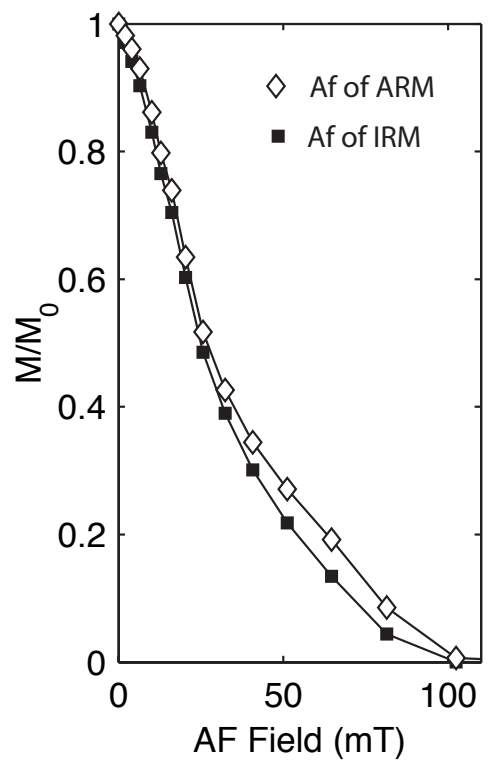

F. RRM: Greigite sclerite

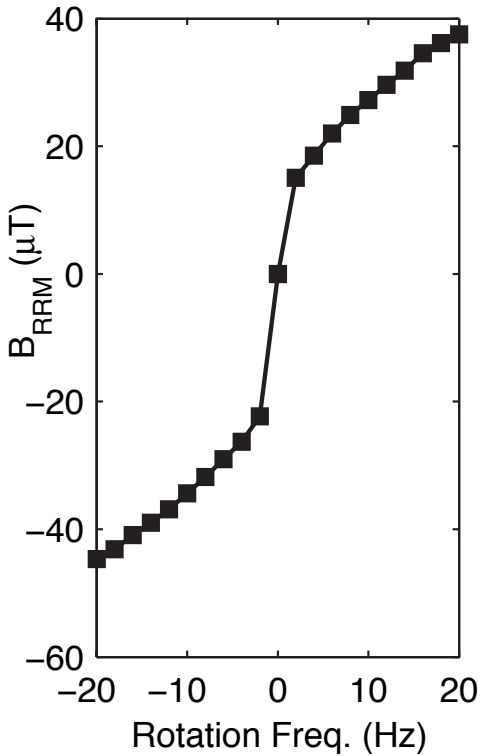

Figure 4: Examples of rock magnetic data generated from the sample-changer system. (A) IRM acquisition and demagnetization of Holocene carbonate sediments, likely magnetofossil-bearing, from a high algal marsh environment on Andros Island, the Bahamas [sample C139+31 cm, Maloof, et al., 2007]. Black curves show IRM moment during acquisition (filled squares) and $\mathrm{AF}$ demagnetization (open squares). Thick, grey curve shows the derivative of the IRM acquisition spectra and illustrates the presence of two distinct phases. (B) ARM acquisition curve for the same sample (black curve with open diamonds). Grey, dashed curves show ARM acquisition for standard single-domain magnetite samples with three-dimensional interparticle interaction effects ranging from minimal at top to strong at the bottom. From top to bottom, standards are intact magnetotactic bacteria, ultrasonicated magnetotactic bacteria, detergent-treated magnetotactic bacteria [all from Kopp, et al., 2006b], and a chiton tooth. (C) The ARM version of the Lowrie-Fuller test [e.g., Johnson, et al., 1975]) for the same sample. If the AF demagnetization of the ARM is harder than that of the IRM, as in this case, the sample tends to be dominated by interacting single-domain particles. 
tray, and all but one include a susceptibility coil. These permit routine bulk susceptibility measurements to be made in conjunction with each remanence measurement for monitoring thermochemical changes during demagnetization (e.g., Fig. 4). The coils also permit AF demagnetization and rock magnetic experiments to be performed automatically. AF demagnetization experiments can be run in the same fashion as standard paleomagnetic measurements, with the system running a single three-axis AF demagnetization step on each specimen in the up-direction measurement and then waiting for the user to flip specimens between steps. Alternatively, the system can perform and measure multiple AF demagnetization steps sequentially on each specimen. This approach permits time-intensive, high-resolution AF demagnetization experiments (e.g., Fig. 3) without user supervision but loses the error check provided by running up-direction and down-direction measurements after each demagnetization level.

The system can similarly impart and measure IRMs (Fig. 4A) and ARMs (Fig. 4B) of specimens. Following Cisowski [1981], IRM measurements can assess intergrain interaction effects. The ARM modification of the classic Lowrie-Fuller test [Johnson, et al., 1975] (Fig. 4C), which compares demagnetization of ARM and IRM, tests the domain state of the magnetic carriers. By spinning specimens in transverse alternating fields, the system can also impart rotational remanence magnetizations (Fig. 4F), which are acquired strongly by iron sulfide minerals like greigite [Snowball, 1997; Suzuki, et al., 2006]. Combination of these techniques enables automation of the Fuller et al. [Fuller, et al., 2002] test for distinguishing the nature of NRM (TRM vs. DRM or CRM) in well-behaved paleomagnetic samples (e.g., Fig. 4D).
Paleomagnetic sample core end chips can be run in rock magnetic experiments using the automated sample pickup system. Other sample shapes, such as powders in tall, narrow quartz-glass NMR tubes, can be loaded manually and fitted to the sample tube using plastic adapters, decreasing the amount of extraneous material exposed to magnetizing fields.

A typical rock magnetic measurement run consists of 20 ARMs imparted in biasing fields increasing stepwise to about $1.6 \mathrm{mT}$, a $\sim 20$-step AF demagnetization of the final ARM, the imparting and $\sim 20$-step AF demagnetization of an IRM acquired in field equivalent to the AF field used in the ARM experiments, the acquisition of $\sim 20$ IRMs in a stepwise increasing field, the stepwise AF demagnetization of the maximum IRM, and a DC backfield demagnetization curve of the maximum IRM. This set of experiments allows the construction of moderately highresolution coercivity spectra, as well as the determination of parameters including IRM and ARM strength, coercivity of remanence, the Cisowski magnetostatic interaction parameter $\mathrm{R}$ [Cisowski, 1981], and ARM susceptibility. Comparison of $\mathrm{H}_{\mathrm{cr}}$ determined rigorously by the DC backfield experiment with median coercivity estimated using Cisowski's protocol (Cisowski, 1981) lets the user evaluate the robustness of $R$. This total $\sim 170$-step experiment takes $\sim 4.5$ hours per specimen and, barring unexpected errors, runs without user supervision. The user is notified of any errors requiring their attention by an email message, which can be set up to announce the problem audibly in the lab. We employ MATLAB scripts to analyze the rock magnetic data. Examples of rock magnetic data produced by the system are published in references including Suzuki et al. [2006], Kopp et al., [2006a; 2006b], and Maloof et al. [2007].

Figure 4, continued: (D) A plot in the style of Fuller [2002] for distinguishing thermal remanent magnetization (TRM) from chemical (CRM) or detrital remanent magnetization (DRM), by comparing the AF stability of NRM (filled circles) and ARM (open diamonds) with that of the IRM. Dashed lines mark different ratios of NRM or ARM to IRM. Data is for an Archean magnetite-bearing siderite sample (Kuruman Formation, Transvaal Supergroup) from the Agouron drill core GKP1 [Schroder, et al., 2006]. (E) Bulk susceptibility and total moment measured at each thermal demagnetization step of an Archean felsic volcanic rock (sample 609D6091.1, Duffer Formation, Pilbara craton, courtesy of Laurent Carporzen at MIT). Susceptibility is a useful tool for monitoring thermochemical changes to the magnetic mineralogy; the curve shown here suggests the formation of a new magnetic phase during heating above $\sim 300^{\circ} \mathrm{C}$. (F) Rotational remanent magnetization of a greigite sclerite produced by the hydrothermalvent "scaly foot" gastropod [data from Suzuki, et al., 2006]. The specimen was fixed in the bottom of a quartz-glass NMR tube, held in-line at the bottom of the sample changer's quartz-glass vacuum tube by a plastic plug, and spun at frequencies between -20 and $+20 \mathrm{~Hz}$ while the transverse AF coil was cycled to peak fields of $100 \mathrm{mT}$. Greigite is particularly susceptible to acquiring RRM in this fashion [Snowball, 1997]. 

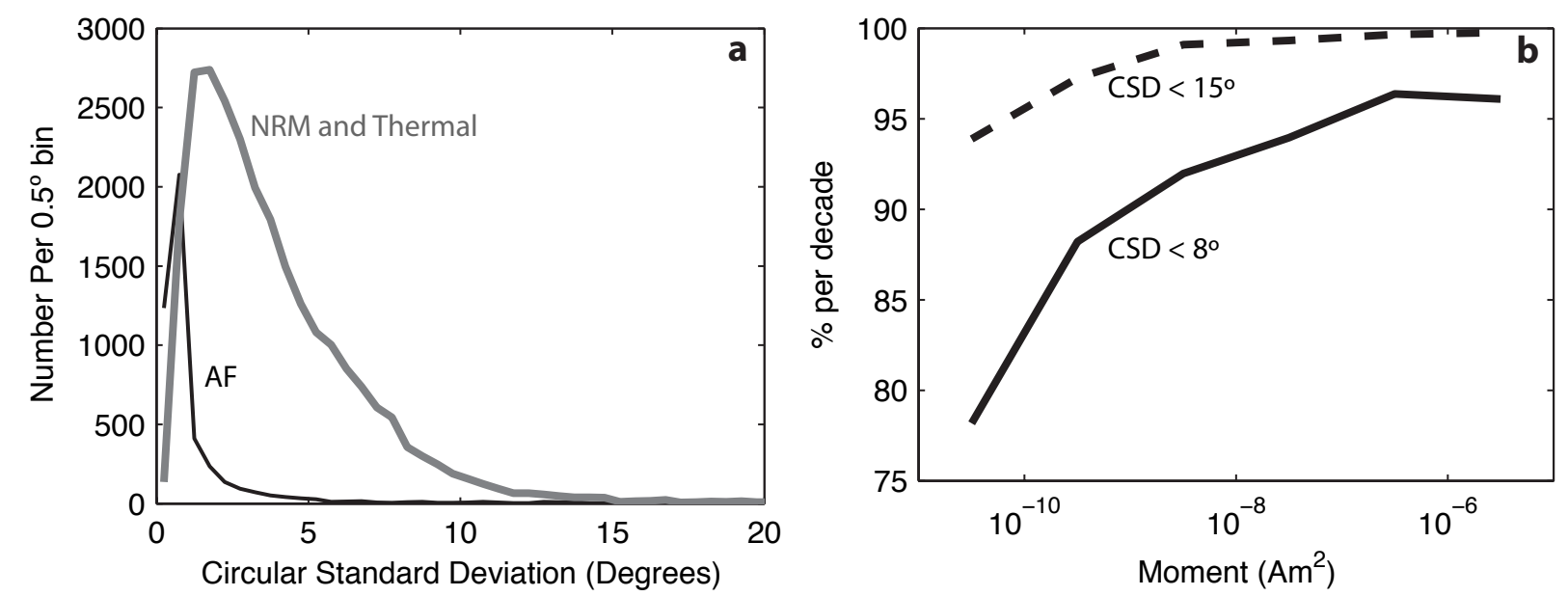

Figure 5: (a) Distribution of circular standard deviations of measurements run on the Eugene Shoemaker Memorial Magnetometer in 2006, either obtained in the course of AF treatments (and generally measured only in the up direction) or NRM and thermal treatment measurements, averaged from measurements in both the up and down directions. Measurements are binned in 0.5 degree steps. (b) Percentage of measurements with circular standard deviations less than 8 and less than fifteen degrees as a function of moment. Measurements are binned by decade.

\section{Assessment of Systematic Errors and Throughput Statistics}

To assess the errors associated with the sample changer system, we identified all samples run in 2006 on one of the two Caltech systems, named the Eugene Shoemaker Memorial Magnetometer, based on the last modification date of sample files. According to that metric, 1,216 samples were run in 2006, a relatively low-use year. The system made 25,858 measurements of NRMs and thermally treated samples (each a composite of at least eight replicate measurements and four "zero" measurements), and it performed and measured 4,619 AF demagnetization steps (most a composite of four replicate measurements and two "zero" measurements). All together, more than $\sim 180,000$ otherwise-manual manipulations were eliminated, or $>800$ per working day. Ordinarily these measurements would require user input every $\sim 20-30$ seconds, effectively monopolizing many working hours.

We typically perform all AF treatments of a sample in series, measuring the sample between each treatment but not averaging together updirection and down-direction measurements. Therefore, the errors associated with AF measurements should reflect the precision of the system. They arise from differences between the sample magnetization as measured in each of the four rotational orientations. The CSDs of all AF measurements are fit by a log-normal distribution centered at 0.5 degrees and with a standard deviation of $0.3 \log$ units (Figure 5a).

NRMs and thermally treated samples, in contrast, are almost always measured in both up and down orientations. The errors associated with the measurements therefore primarily reflect the accuracy of the system and are dominated by the effects of sample orientation. The CSDs of all such measurements are fit by a log-normal distribution centered at 1.7 degrees and with a standard deviation of $0.5 \mathrm{log}$ units. The distribution has a kink at 8 degrees associated with the error checking routines described above (Figure 5a). Altogether, $91.6 \%$ of the measurements have CSDs less than 8 degrees; only $1.7 \%$ have CSDs greater than 15 degrees.

Of the NRM and thermal treatment steps, 9.6\% had to be re-measured at least once. $80.8 \%$ of the steps requiring remeasurement had CSDs greater than 8 degrees, and the large majority of these would have been rerun after the software prompted the user. We found that $45.3 \%$ had CSDs greater than 15 degrees. After remeasurement, only $24.0 \%$ had CSDs greater than 8 degrees, and only $10.1 \%$ had CSDs greater than 15 degrees.

CSDs increase with declining sample moment, as expected (Figure 5b). The median moment of all NRM and thermal treatment measurements with CSDs less than 8 degrees was $370 \mathrm{pAm}^{2}$, while the median moment of all such 
measurements with CSDs greater than 15 degrees was $28 \mathrm{pAm}^{2}$.

Propagation of these measurement errors to magnetization imprecision will decrease as the number of demagnetization steps employed for a specimen increases. Based on the log-normal distribution of errors, magnetizations measured at ten demagnetization steps, for instance, will have mean CSDs of 1.2 degrees, and $95 \%$ of such magnetizations will have CSDs less than 2.2 degrees. Corresponding 95\% confidence intervals for these magnetizations will be 1.73 times the CSDs [Creer, 1970]. This figure can be compared with magnetization uncertainty produced by manual paleomagnetic measurements.

Figure 6 bins $95 \%$ confidence uncertainties of directional magnetization distributions reported for Cenozoic extrusive igneous units all over the world. While several signals and biases surely affect the resulting distribution of dispersions, two patterns appear clearly. First, the youngest global dataset of extrusive igneous units $(0-1 \mathrm{Ma})$ is characteristically 1.5-3 times more precise than any characteristic dispersion of units at any older Cenozoic age. This suggests that many paleomagnetic studies, even of "fresh" volcanic rocks not subject to tectonic reworking, fail to achieve the precision "expected" by the bestpreserved such rocks. Second, despite this tendency for mean dispersion at $>1 \mathrm{Ma}$ to be
1.5-3 times higher than mean dispersion in rocks erupted in the past million years, the most precise studies of all ages approach $\sim 1.0^{\circ}-2.0^{\circ}$ with $95 \%$ confidence uncertainty.

Because some sampling effects, which should be least biasing in the 0-1 Ma dataset, may artificially diminish this uncertainty, we suggest a reasonable interpretation of the global Cenozoic volcanic record is that the limit of unbiased paleomagnetic precision is $\pm 1.5^{\circ}-2.0^{\circ}$. This result is less than half the conventionally quoted value of $\pm 5^{\circ}$ imprecision, which accords more closely with the long-term mean uncertainty observed for binned distributions. We suspect that the paleomagnetic precision limit of $\pm 1.5^{\circ}-2.0^{\circ}$ is caused largely by unavoidable orientation imprecision in the field (including rounding) and that the enhanced uncertainty more frequently observed reflects fewer-than-ideal sample numbers and less-intense-than-ideal progressive demagnetization leading to under-resolved vector magnetizations. The automated sample changing system is no less precise than the best of conventional, manual sample changing studies, and possibly it is generally better (especially on the several-hundredth consecutive measurement of a series).

\section{Discussion}

Figure 6, next page: (a) Binned distribution (with $95 \%$ confidence interval of mean uncertainties shown in gray) of $95 \%$ confidence uncertainties around the directional mean for 619 paleomagnetic studies of "Cenozoic" extrusive igneous rocks from all continents (aged $0-66 \mathrm{Ma}$ ), taken from the IAGA Dragon International Paleomagnetic Database (http://www.ngu.no/dragon/Palmag/paleomag.htm) on October 7, 2007. (b) Closeup (cropped to $\alpha_{95}<15^{\circ}$ ) of the binned distribution of $95 \%$ confidence uncertainties around the directional mean for 267 paleomagnetic studies of young extrusive igneous rocks from all continents (aged $0-5 \mathrm{Ma}$ ). Dispersion within bins of both plots arises from several sources. Low number of sampled units may bias dispersion to anomalously low or erroneously high values. Geomagnetic field effects may introduce true differential dispersion by a factor of $\sim 2+$, varying with latitude of the sampling site, and intrinsic variability of the geomagnetic field over timescales of $\sim 10,000$ 's years may vary within bins of $1 \mathrm{Myr}+$. However we suspect that a significant portion of the dispersion of directional uncertainty within bins arises from incomplete characterization of primary remanence due to fewer-than-ideal demagnetization steps per specimen; and fewer-than-ideal number of samples per site or formation. Despite ambiguities, two characteristics of this dataset appear prominent. First, the majority of paleomagnetic studies older than $1 \mathrm{Ma}$ have average uncertainty $\sim 1.5-3$ times greater than average uncertainty in paleomagnetic studies of extrusive igneous rocks erupted in the last million years. Second, paleomagnetic studies of all Cenozoic ages converge to a lower uncertainty of $\sim 1.5^{\circ}-2.0^{\circ}$. We suspect this represents the intrinsic precision limitation of paleomagnetic study, due to errors introduced during sample orientation in the field. Certainly, conventional quotation of " $5^{\circ}$ " as the limit of paleomagnetic resolution may be frequently accurate in observation, but pessimistic in principle by a factor of $\sim 2$. Database results were excluded from analysis only if a) they studied a single cooling unit; b) $\alpha_{95}>30^{\circ}$; c) they measured NRM only; or d) age was uncertain to greater than $\pm 2.5 \mathrm{Myr}$ (for mean ages 0 $10 \mathrm{Ma}$ ), $\pm 4 \mathrm{Myr}$ (for mean ages 10 - $30 \mathrm{Ma}$ ), $\pm 5 \mathrm{Myr}$ (for mean ages 30 - $66 \mathrm{Ma}$ ). Data with age ranges were assigned mean ages with preference toward next-greatest integer age values. This protocol appears to be conservative relative to our interpretations. 

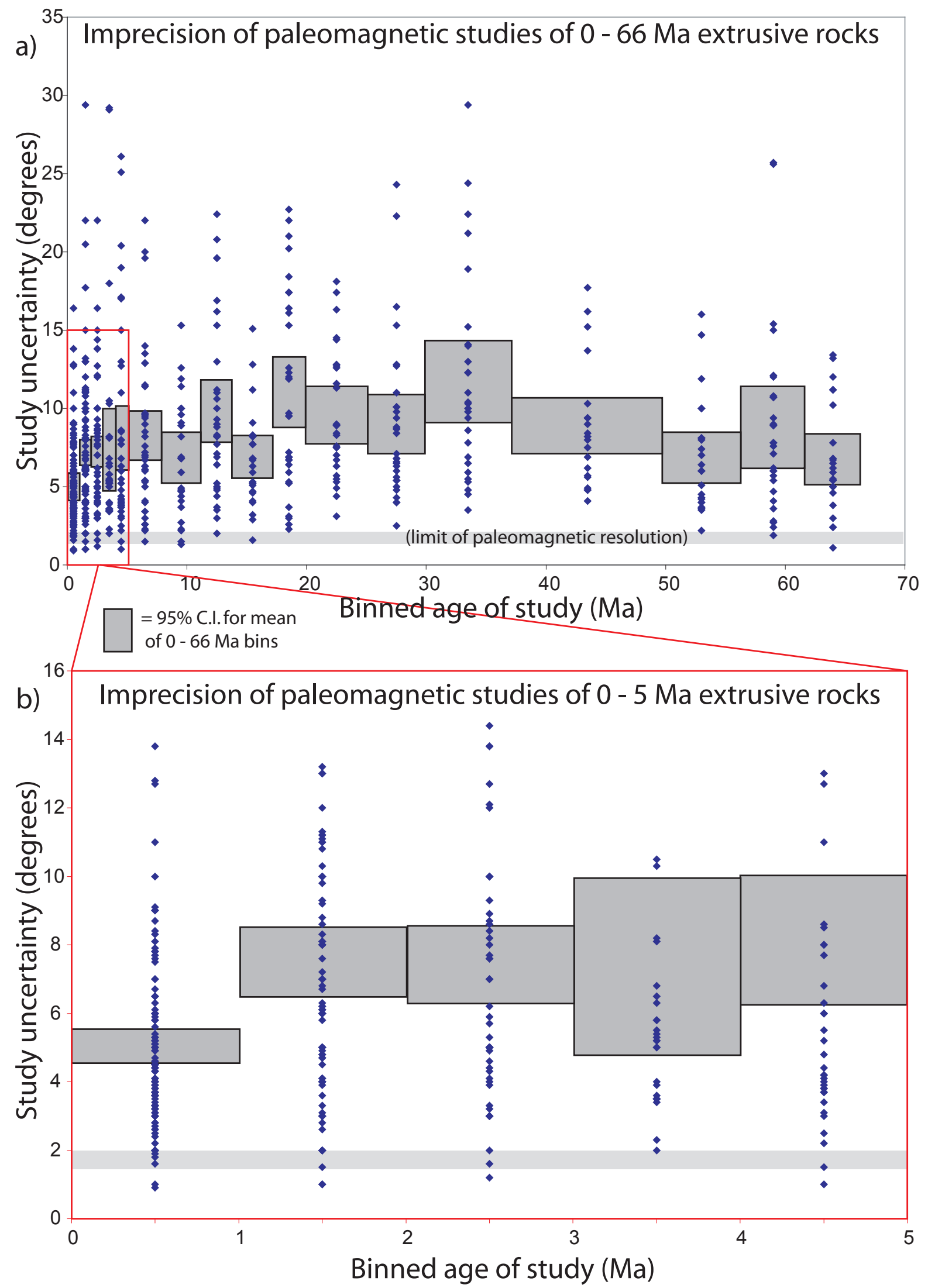
In the past three years, the Caltech sample changer system has been implemented in facilities at Occidental College, the Massachusetts Institute of Technology, Yale University, the University of Texas at Austin, and the United States Geological Survey laboratory in Menlo Park, California, and several more systems are in the construction or planning stages. During this time, the benefits of having an intermural consortium of laboratories sharing in the design, construction, maintenance, and improvement of the paleomagnetic instrumentation and software have become clear. Among other benefits, the consortium allows us to take advantage of the open source model of software development [Raymond, 2001]. Features needed by one member of the consortium can be developed locally and then tested and improved almost immediately at other labs. While in some scientific disciplines, such as geochemistry, the community of users is large enough to drive innovations through marketplace competition among commercial firms, this does not appear to be the case for paleomagnetics. Open source collaboration, driven by the desire to "scratch a developer's personal itch," [Raymond, 2001] is ideal for such a situation. Resulting improvements to date include better flux-jump suppression, enhanced error checking and control of the AF demagnetization system, and more precise positioning of samples in the coils.

User-based development has also led to a gradually improving ability to perform a detailed and informative array of rock magnetic experiments. These have expanded from the simple 3-axis AF demagnetization of the NRM to include all of the examples now shown in Figure 4. Ongoing developments include acquisition of classic backfield IRM Preisach distributions [Bate, 1962; Carvallo, et al., 2005], which contain data similar to that present in first order reversal curves (FORC diagrams), via the classic backfield IRM Preisach distribution. Although hundreds of IRM measurement cycles, spanning many hours of magnetometer time, are required for this, most of the nearly 100 superconducting rock magnetometers now in existence are currently inactive much of the time despite being held at liquid helium temperatures continuously. Implementation of the sample changing system, however, can change that dramatically - multiuser demand for directional paleomagnetic measurements kept the Yale magnetometer operating more than 20 hours per day, $\sim 360$ days per year through 2005 and 2006. Superconducting susceptometers like the Quantum Design MPMS systems are routinely used for many hours at a time on individual specimens, and there is no reason that SQUID rock magnetometers could not be used in a similar fashion.

The prognosis is good for expansion of the sample changer consortium at a reasonable rate of a few instruments per year, largely through cooperative co-construction agreements. $2 \mathrm{G}$ Enterprises reports having built nearly 100 SQUID systems, most of which are still operational. Most of these are cooled by liquid helium and can be operated either in horizontal orientation or in the vertical orientation required by our sample changer system. However, newer units that use pulse-tube cryocoolers instead of liquid helium cannot be rotated, as the pulse-tubes must be vertical to run properly; although we are experimenting with designs for horizontallyoriented systems, we advise users interested in an automatic sample changer system to acquire vertically-oriented systems. With their smaller size, they will also reduce the vertical clearance needed for the sample handler system. Given enough interest from the community, we expect that the cost of building a sample changer system can be significantly reduced by methods such as using injection-molding techniques to mass produce the Delrin ${ }^{\mathrm{TM}}$ plastic parts. Future hardware improvements could include in-line microwave demagnetization and perhaps measurement of IRM or ARM anisotropy. It may also be possible to control the AF demagnetization process directly from the controlling computers, using 16 bit or better resolution; at least one of the commercially-available AF controller still relies nearly three-decade old 12-bit technology.

\section{Conclusions}

Under normal operating conditions, the automatic sample changer described here averages $\sim 30$ specimens per hour, measured in both up and down directions. Thus, for a typical 60 -specimen sample set, the measurement portion of a highresolution 40-step thermal demagnetization process can be completed within four days of continuous operation. Reduction in the background noise of sample holders permits measurements of weakly magnetized carbonates with moments of a few $\mathrm{pAm}^{2}$, with further increases in sensitivity still possible. Analysis of the errors on sample measurements from one year 
of operation confirms that the system produces accurate data. Meta-analysis of the error distributions associated with paleomagnetic studies of Cenozoic volcanic rocks indicates that many studies sport $\sim 200 \%$ of the characteristic uncertainty associated with the most recent, presumably least-complicated and best-exposed volcanic rocks, and few studies approach the apparent limit of paleomagnetic resolution, $\pm 1.5^{\circ}$ (95\% confidence). This "ideal" level of paleomagnetic resolution should be more routinely obtainable with more demagnetization steps per specimen and samples per study unit. Automating paleomagnetic and rock magnetic measurements with systems like the one described here frees the researcher from the role of handmaiden to the magnetometer and promotes the creation of rich data sets while liberating time for experimental design and data analysis. A consortium of laboratories sharing a common platform fosters development of new features and more efficient and precise techniques.

\section{Acknowledgements}

The refinement of the sample changer has been supported by a continent-wide consortium of faculty, including Scott Bogue (Occidental College), David Evans (Yale), and Benjamin Weiss (MIT). Numerous students in, and visitors to, the Caltech lab helped debug the system. Victor Nenow gave much advice on earlier versions of the controlling electronics, and Ricardo Paniagua of the Caltech Physics shop solved the problem of mass-producing the plastic cups for the snake chain. Former students Gaylon Lovelace, Hiroshi Iishi, Bryce Engelbrecht, Theresa Raub, and Isaac Hilburn played key roles in constructing the early versions of the sample changer and software at Caltech, and modern incarnations at Yale and MIT. Research support over the past 25 years from the NSF, NASA, $\mathrm{NIH}$, the Agouron Institute, and the Caltech SURF program made these developments possible. We thank Joshua Feinberg and Craig Jones for insightful reviews.

\section{References}

As, J. A., and J. D. A. Zijderveld (1958), Magnetic Cleaning of Rocks in Palaeomagnetic Research, Geophys. J. Roy. Astron. Soc., 1, 308-319.

Bate, G. (1962), Statistical Stability of Preisach diagram for particles of $\gamma-\mathrm{Fe}_{2} \mathrm{O}_{3}$, J. Appl. Phys., 33, 2263-2269.

Carvallo, C., D. J. Dunlop, and O. Ozdemir (2005), Experimental comparison of FORC and remanent Preisach diagrams, Geophys. J. Int., $162,747-754$.
Channell, J. E. T., J. H. Curtis, and B. P. Flower (2004), The Matuyama-Brunhes boundary interval (500-900 ka) in North Atlantic drift sediments, Geophys. J. Int., 158, 489-505.

Cisowski, S. (1981), Interacting vs. non-interacting single-domain behavior in natural and synthetic samples, Phys. Earth Planet. Int., 26, 56-62.

Cogne, J. P. (2003), PaleoMac: A Macintosh ${ }^{\mathrm{TM}}$ application for treating paleomagnetic data and making plate reconstructions, Geochem. Geophys. Geosys., 4, 1007 , doi: 10.1029/2001GC000227.

Collinson, D. W. (1983), Methods in Rock Magnetism and Paleomagnetism, 503 pp., Chapman and Hall, New York, N.Y.

Creer, K. M. (1970), A Palaeomagnetic Survey of South American Rock Formations: General Introduction, Phil. Trans. Roy. Soc. A, 267, 458-462.

Dunlop, D. J., and O. Ozdemir (1997), Rock Magnetism: Fundamentals and Frontiers, 573 pp., Cambridge University Press, New York.

Egli, R. (2004), Characterization of individual rock magnetic components by analysis of remanence curves, 1. Unmixing natural sediments, Stud. Geophys. Geod., 48, 391-446.

Enkin, R. J. (2003), The direction-correction tilt test: an all-purpose tilt/fold test for paleomagnetic studies, Earth Planet. Sci. Lett., 212, 151-166.

Fuller, M., W. S. Goree, and W. L. Goodman (1985), An introduction to the use of SQUID magnetometers in Biomagnetism, in Magnetite Biomineralization and Magnetoreception in Organisms: A New Biomagnetism, edited by J. L. Kirschvink, et al., pp. 103-151, Plenum Press, New York.

Fuller, M., T. Kidane, and J. Ali (2002), AF demagnetization characteristics of NRM, compared with anhysteretic and saturation isothermal remanence: an aid in the interpretation of NRM, Phys. Chem. Earth, 27, 1169-1177.

Goree, W. S., and M. Fuller (1976), Magnetometers Using Rf-Driven Squids and Their Applications in Rock Magnetism and Paleomagnetism, Rev. Geophys., 14, 591-608.

Isozaki, Y., H. Kawahata, and A. Ota (2007), A unique carbon isotope record across the GuadalupianLopingian (Middle-Upper Permian) boundary in mid-oceanic paleo-atoll carbonates: The highproductivity "Kamura event" and its collapse in Panthalassa, Global Planet. Change, 55, 21-38, doi:10.1016/j.gloplacha.2006.06.006.

Johnson, H. P., W. Lowrie, and D. V. Kent (1975), Stability of ARM in fine and course grained magnetite and maghemite particles, Geophys. J. Roy. Astron. Soc., 41, 1-10. 
Jones, C. H. (2002), User-driven integrated software lives: "Paleomag" paleomagnetics analysis on the Macintosh, Comput. Geosci., 28, 1145-1151.

Kent, J. T., J. C. Briden, and K. V. Mardia (1983), Linear and Planar Structure in Ordered Multivariate Data as Applied to Progressive Demagnatization of Paleomagnetic Remanence, Geophys. J. Roy. Astron. Soc., 75, 593-621.

Kirschvink, J. L. (1980), The Least-Squares Line and Plane and the Analysis of Paleomagnetic Data, Geophys. J. Roy. Astron. Soc., 62, 699-718.

Kirschvink, J. L. (1981), How sensitive should a rock magnetometer be for use in paleomagnetism?, in SQUID Applications to Geophysics., edited by H. Weinstock and W. C. Overton, pp. 111-114, The Society of Exploration Geophysicists, Tulsa, Oklahoma.

Kirschvink, J. L. (1983), Ch. 14: Biogenic ferrimagnetism: a new biomagnetism, in Biomagnetism: An Interdisciplinary Approach., edited by S. Williamson, pp. 501-532, Plenum Press, New York, N.Y.

Kirschvink, J. L. (1992), Uniform magnetic fields and Double-wrapped coil systems: Improved techniques for the design of biomagentic experiments, Bioelectromag., 13, 401-411.

Kirschvink, J. L., and H. A. Lowenstam (1979), Mineralization and magnetization of chiton teeth: Paleomagnetic, sedimentologic, and biologic implications of organic magnetite, Earth Planet. Sci. Lett., 44, 193-204.

Kirschvink, J. L., and Y. Isozaki (2007), Extending the Sensitivity of Paleomagnetic Techniques: Magnetostratigraphy of Weakly-Magnetized, Organic-Rich Black Limestone from the Permian of Japan, paper presented at American Geophysical Union Fall Meeting, American Geophysical Union, San Franciso.

Kobayashi, A. K., J. L. Kirschvink, and M. H. Nesson (1995), Ferromagnetism and EMFs, Nature, 374, 123-123.

Kopp, R. E., C. Z. Nash, A. Kobayashi, B. P. Weiss, D. A. Bazylinski, and J. L. Kirschvink (2006a), Ferromagnetic resonance spectroscopy for assessment of magnetic anisotropy and magnetostatic interactions: A case study of mutant magnetotactic bacteria, J. Geophys. Res., 111, B12S25, doi:10.1029/2006JB004529.

Kopp, R. E., B. P. Weiss, A. C. Maloof, H. Vali, C. Z. Nash, and J. L. Kirschvink (2006b), Chains, clumps, and strings: Magnetofossil taphonomy with ferromagnetic resonance spectroscopy, Earth Planet. Sci. Lett., 10-25, doi:10.1016/ j.epsl.2006.05.001

Lee-Whiting, G. E. (1957), Uniform Magnetic Fields, Report CRT-673, 28 pp, Atomic Energy of Canada, Ltd., Chalk River Project Research and Development, Ottawa.
Maloof, A. C., R. E. Kopp, J. P. Grotzinger, D. A. Fike, T. Bosak, H. Vali, P. M. Poussart, B. P. Weiss, and J. L. Kirschvink (2007), Sedimentary Iron Cycling and the Origin and Preservation of Magnetization in Platform Carbonate Muds, Andros Island, the Bahamas, Earth Planet. Sci. Lett., 259, 581-598, doi:10.1016/j.epsl. 2007.05.021.

Nagy, E. A., and J. P. Valet (1993), New Advances for Paleomagnetic Studies of Sediment Cores Using U-Channels, Geophys. Res. Lett., 20, 671-674.

Raymond, E. S. (2001), The Cathedral and the Bazaar, 241 pp., O’Reilly Media, Sebastapol, California, USA.

Roberts, A. P. (2006), High-resolution magnetic analysis of sediment cores: Strengths, limitations and strategies for maximizing the value of long-core magnetic data, Phys. Earth Planet. Int., 156, 162-178, doi:10.1016/j.pepi. 2005.03.021.

Schmidt, P. W. (1982), Linearity Spectrum Analysis of Multicomponent Magnetizations and its Application to some Igneous Rocks from Southeastern Australia, Geophys. J. Roy. Astron. Soc., 70, 647-665.

Schroder, S., J. P. Lacassie, and N. J. Beukes (2006), Stratigraphic and geochemical framework of the Agouron drill cores, Transvaal Supergroup (Neoarchean-Paleoproterozoic, South Africa), S. Afr. J. Geol., 109, 23-54.

Scott, G. R., and C. Frohlich (1985), Large-Volume, Magnetically Shielded Room: A New Design and Material, in Magnetite Biomineralization and Magnetoreception in Organisms: A New Biomagnetism, edited by J. L. Kirschvink, et al., pp. 197-222, Plenum Press, New York \& London.

Snowball, I. F. (1997), The detection of single-domain greigite (Fe3S4) using rotational remanent magnetization (RRM) and the effective gyro field (Bg): Mineral magnetic and palaeomagnetic applications, Geophys. J. Int., 130, 704-716.

Suzuki, Y., R. E. Kopp, T. Kogure, A. Suga, K. Takai, S. Tsuchida, N. Ozaki, K. Endo, J. Hashimoto, Y. Kato, C. Mizota, T. Hirata, H. Chiba, K. H. Nealson, K. Horikoshi, and J. L. Kirschvink (2006), Sclerite formation in the hydrothermalvent "scaly-foot" gastropod--possible control of iron sulfide biomineralization by the animal, Earth Planet. Sci. Lett., 242, 39-50, doi:10.1016/ j.epsl.2005.11.029.

Tauxe, L., and D. V. Kent (2004), A simplified statistical model for the geomagnetic field and the detection of shallow bias in paleomagnetic inclinations: Was the ancient magnetic field dipolar?, in Timescales of the Paleomagnetic field, Geophysical Monograph, edited by J. E. T. 
Channell, et al., pp. 101-116, American Geophysical Union.

Valet, J. P., L. Meynadier, and Y. Guyodo (2005), Geomagnetic dipole strength and reversal rate over the past two million years, Nature, 435, 802-805, doi:10.1038/nature03674.

van der Voo, R. (1990), The reliability of paleomagnetic data, Tectonophysics, 184, 1-9.

Verosub, K. L. (1998), Paleomagnetism - Faster is better, Science, 281, 1297-1298.

Walker, M. M., J. L. Kirschvink, A. S. Perry, and A. E. Dizon (1985), Methods and Techniques for the Detection, Extraction, and Characterization of Biogenic Magnetite, in Magnetite Biomineralization and Magnetoreception in Organisms: A New Biomagnetism, edited by J. L. Kirschvink, et al., pp. 154-166, Plenum Press, New York.

Weiss, B. P., F. J. Baudenbacher, J. P. Wikswo, and J. L. Kirschvink (2001), Magnetic microscopy promises a leap in sensitivity and resolution, Eos Trans. AGU, 82, 513 \& 518. 